\title{
The Role of Hearts \& Minds in Organisational Change
}

\section{Davies C*}

PhD, CPsychol, CMgr, FCMI, HCPC

Loughborough University, UK

Abstract

The aims of this paper are as follows:

1. To put Hearts \& Minds on the map as a key approach to organisational change.

2. To explain the underlying mechanism of Hearts \& Minds.

3. To show that Hearts \& Minds can be equally successfully deployed for organisational change in the commercial sector.

4. To explain how Hearts \& Minds achieves a higher level of permanence compared with other approaches.

The paper traces the military origins of Hearts \& Minds from the Malayan Emergency and the Borneo Campaign through to the final version in Operation Storm. The method centres around working within the values of the target audience, focusing on the needs of that audience and mimicking the military model. The results from the commercial adaptation are equally reliable as in the military model and permanence of the transformation is equally present.

The key reasons why Hearts \& Minds is effective and reliable is as follows:

- In an inverted way, fixes problems that are important to the target audience, neither the Administrators nor C-suite

- Addresses Needs \& Wants of the target audience

- Allows the target audience to participate

- The target audience are given the skills by a Training Team who chaperone them throughout the task

- The Training Team always work within the values of the target audience

- Achieves a high level of permanence

- Dignity is maintained at all times

Keywords: Training Team, Needs \& Wants, Permanence, Values, Communication, Awareness

\section{Introduction}

Hearts \& Minds was conceived by Sir Gerald Templer, the British High Commissioner for Malaya, during the Malayan Emergency. The exact moment at which he first used the phrase 'winning the hearts and minds of the people' does not seem to be officially recorded, but it was very soon after his arrival. It was a telling phrase and caught on rapidly". The Malayan Emergency lasted from 1948-1960. "The shooting side of the business is only $25 \%$ of the trouble and the other $75 \%$ lies in getting the people of this country behind us", wrote Templer in November 1952.
This required the notion of understanding people's needs and desires and linking those desires to a sensible civil development programme. It meant delivering it without qualification, yet undertaking all of this within the culture of the people, rather than the culture of the change agents. Gathering intelligence constantly and communicating free of propaganda always took place within the context of the civil developments in progress. Issues were dealt with as they arose.The outcome was success.

Due to the similarity between the Malayan and Borneo jungles, Hearts \& Minds was again deployed in the Borneo Campaign lasting

\begin{tabular}{|l|l|}
\hline \hline Quick Response Code: & FCorresponding author: Chris Davies, Chris Davies \& Associates, Gerrards Cross, Bucks, SL9 \\
$9 \mathrm{AH}, \mathrm{UK}$ & \multicolumn{1}{c}{ Published: 24 May, 2021} \\
Received: 20 April, 2021 & \\
Citation: Davies C. The Role of Hearts \& Minds in Organisational Change. J Psych Sci Res. \\
2021;1(2):1-13. D0I: 10.53902/JPSSR.2021.01.000507
\end{tabular}


from 1963-1966. ${ }^{2}$ The focus again was working within the values of the tribesmen, which included living in their longhouses as well as providing medical care and paying for their assistance with helipad land clearance. Intelligence gathering was also a key component.

Years later, the concept of Hearts \& Minds was deployed again in Dhofar, the province covering Southern Oman. A key strategy of the British Army's Operation Storm, (1969-1976) and subject to a D-Notice until the Army's disengagement, Operation Storm ${ }^{3}$ not only repelled a communist invasion, but also developed a civilisation in sympathy with the values of the country. Gradually but surely, the fighters who had seen themselves as communists were drawn to the new Sultan's ideals, leaving behind their allegiance to communism. In effect, it took Hearts \& Minds one step beyond the results achieved in Malaya and Borneo.

Hearts \& Minds presents a common thread throughout any organizational restructuring, be it part of a military campaign or challenges in the commercial field. Even where there is a lack of correlation a strong analogous relationship still persists. Crucially, Hearts \& Minds does not involve coercion: it is founded on persuasion. Further, it does not use dictatorship or ordering. Instead, it involves changing attitudes, appealing to people and motivating them. In the commercial model, this is represented by a dual approach whereby the installation of a team culture is encouraged by presenting to them missions and objectives initiated at the corporate level, followed by cascading them down throughout the entire organisation. By enabling people to do things differently, it acts to open their minds. Once doing things differently creates perceived success, people are convinced of their abilities and thus become motivated to continue. A successful conclusion occurs when the people have identified with the new ideas; they have assimilated them and then internalised the ideas to become additional to their own set of beliefs. The author carried out research ${ }^{4}$ in 1991, to understand the underlying mechanisms and then translated them into a form, which could be used in a commercial organisation. This was then trialed at a large organisation ${ }^{4}$ with excellent results achieved.

This pilot exercise confirmed that the techniques translated into the commercial arena generated results on a par with the military. The methodology was then developed to include a formal Climate Survey and an Organisational Development Plan (ODP). This final version was deployed to achieve cultural change in the IT Division of a large insurance company, totaling 550 people, whose success was recognised widely by their winning awards. A version of the ODP was then adapted for a service provider, delivering at the time a novel system for an insurance company with 350 staff. This company went on to win a top industry award. A further reiteration featured a technology-driven communications company with 3,500 employees, having experienced exponential growth. In this case, the ODP was not completed by the time the company was placed in
Administration, but nevertheless results achieved were equivalent to those achievements outlined above. Major projects in the Public Sector adapting and adopting the Hearts \& Minds methodology have achieved success equal to the cases above, notably in the NHS. Particularly effective were aspects relating to working within the culture of the target audience, awareness, communication and the formation of a Training Team.

\section{What are hearts and minds? ${ }^{5}$}

- A simple methodology, not a closed-loop process which

- Adds to the existing beliefs of the audience

- Knows what is important to the audience and within their value system

- $\quad$ Communicated honestly in a consistent and in an all embracing way

- Gathers awareness for honest progress measurement

- $\quad$ Activates and channels effort through a 'Training Team'

- $\quad$ Achieves a macro vision

\section{Characteristics of a training team}

- $\quad$ Not being there when not needed

- $\quad$ Being there when it counts and sharing accountability with the audience

- $\quad$ Infusing scarce KES

- $\quad$ Target role models both in terms of KES and behaviours

- $\quad$ Always available by being located in a house/office where the audience can visit on demand

- Works alongside the audience, but without membership

\section{Some benefits}

- $\quad$ Performance through belief

- Internalised change

- $\quad$ Avoids cognitive dissonance

- $\quad$ Constant feedback instead of infrequent surveys

- $\quad$ Focus on the target value system

- An objective is self-sufficiency

- Turnaround rather than dispensing

- Uniquely proven and reliable

\section{Summary}

The table below shows the commercial counterparts [Your Situation] of the military model (Figure 1): 


\begin{tabular}{|l|l|}
\hline \multicolumn{1}{|c|}{ H \& M } & "YOUR SITUATION " \\
WHAT IS THE OBJECTIVE ? & \\
CIVIL DEVELOPMENT PROGRAMME & SUN LIFE "VISION" \\
NEEDS \& WANTS & YOUR OWN \\
INTELLIGENCE & ONLY AWARENESS (NO ENEMY) \\
INFORMATION & AS IS $\uparrow$ \\
TRAINING TEAM & KEY MAGIC CIRCLE PLAYERS \\
RAISING FIRQUATS & RAISING YOUR DEPARTMENTS \\
LOYAL TO THE SULTAN & LOYAL TO VISION / ODP, ETC. \\
\hline SEPS & 三 BORROW THE SAME APPROACH \\
& FOR "CONVERTS' \\
\hline
\end{tabular}

Figure 1: Comparison between Military and Commercial components.

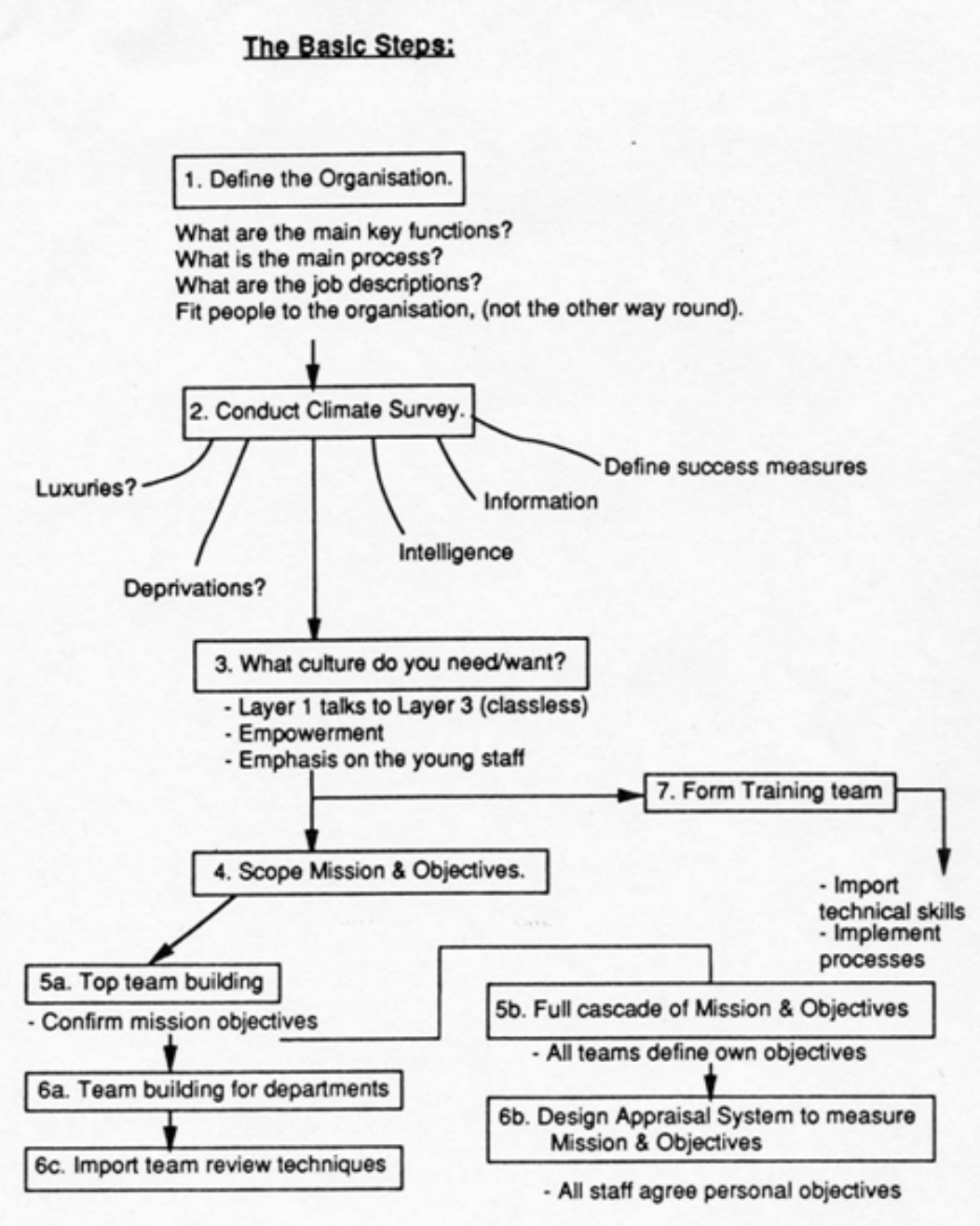

Figure 2: The Basic Steps. 
- $\quad$ The vision maps directly to 'The Basic Steps' as Step 4

- $\quad$ Needs \& Wants remain unchanged

- Intelligence has been transposed into Awareness

- Information has been transposed into communication and remains unchanged

- Training Team remains unchanged

- Loyalty remains unchanged

- $\quad$ SEPs ${ }^{\text {II }}$ - this approach is applied to converts, when they became loyal to the ODP.

\section{Method}

The original research paper ${ }^{4}$ described a simple methodology translated from the military context called 'The Basic Steps' shown in Figure 2.

This encapsulated the commercial transformation of Hearts \& Minds, covering:

- Defining the organisation

- $\quad$ Conducting the Climate Survey

- What culture is needed?
- $\quad$ Training Team formation

- $\quad$ Scoping Mission \& Objectives

- $\quad$ Top Team formation

- $\quad$ Teambuilding/Appraisal system

It featured all the mechanisms of Hearts \& Minds-see Steps 2 and 7 and was used for the pilot.

This simplified methodology neither included measurable diagnosis of the organisation, nor the identification of remedial steps required for the organisation to realise its stated purpose. As already mentioned in the Introduction, prior to full scale deployment at the first insurance organisation, the adapted Hearts \& Minds approach was trialed in the IT Division of a smaller organisation, which consisted of 100 staff spread over eight international centres.

The results are summarised in the next Section.

The final version of the methodology included a formal Climate Survey ${ }^{6}[$ Step 2] and an ODP, which are now discussed. Before Hearts \& Minds was deployed, a Climate Survey ${ }^{7}$ was undertaken, which measured how the IT Division [MSD] saw themselves and how their Customers [Users] viewed them. The results are shown below in Figure 3:

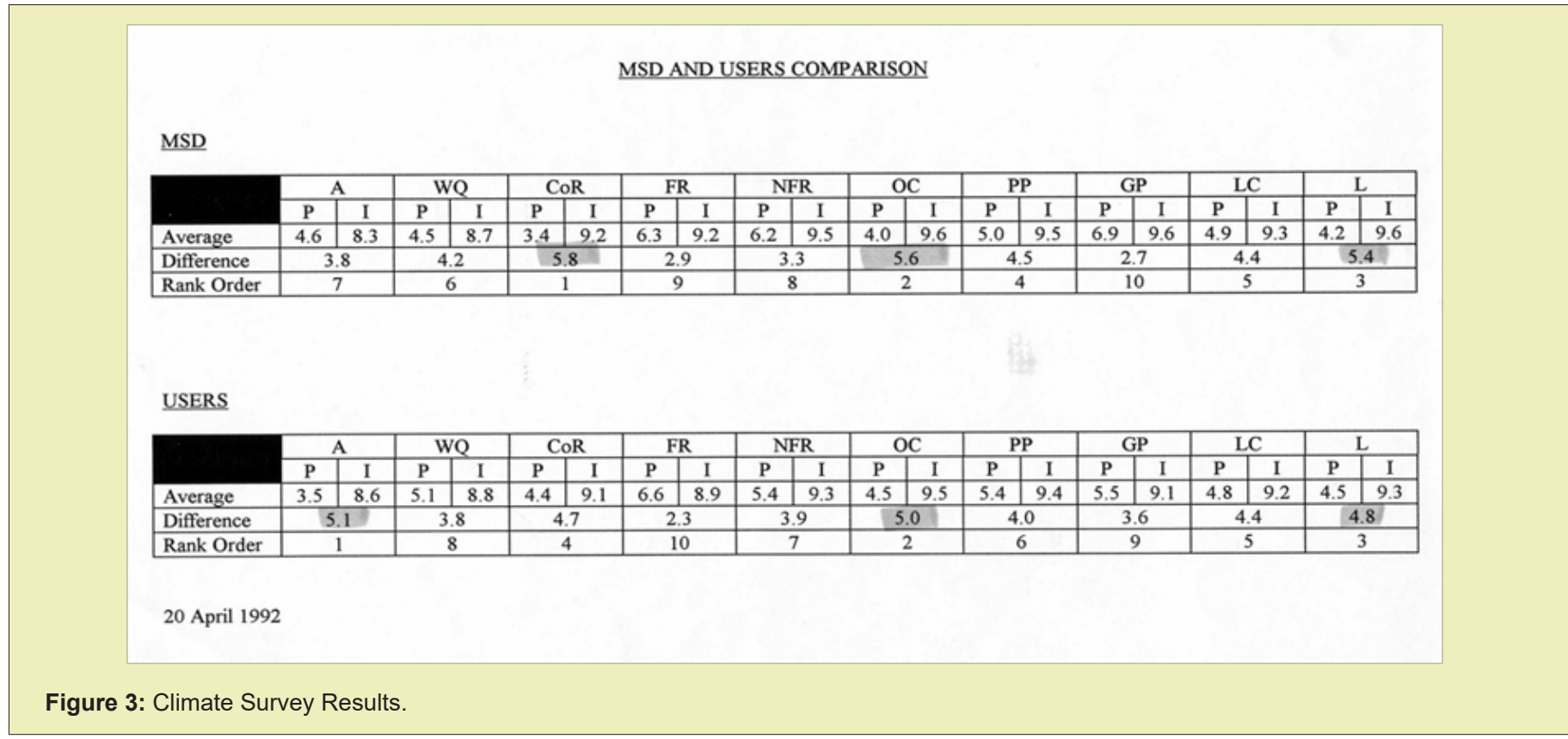

Some abnormally high variances ${ }^{I I I}$ between where people thought they should be and their current position were recorded, these being shown below:

- $\quad$ Clarity of Responsibility (CoR) (5.8)

- $\quad$ Organisational Clarity (OC) (5.6)
- $\quad$ Leadership (L) (5.4)

Additionally, the Users also added

- $\quad$ Adaptiveness (A) (5.1)

Past history showed that the target audience [MSD] was very resistant to change and also diagnosed that dignity had been lost. ${ }^{8}$

"Surrendered Enemy Personnel

I'At the time, the highest ever recorded 
The challenge of the migration programme ${ }^{\mathrm{IV}}$ with which they were engaged was daunting and the software was undocumented to ensure job security. Over the last 10 years, their track record had been poor and a form of laziness had developed. To ensure the onus for change was vested in the target audience an intervention technique was used where by the specific task was described in a project brief, which was assigned to a chosen team, who were then supported by a Training Team member. In design terms, the target team was not involved in electing the task, but were given great freedom on how it was tackled.
Whenever, they hesitated, they were offered benchmark visits to other organisations. They were only ever empowered to execute the project briefs as named individuals without delegation, so that ownership always remained with them. The assigned Training Team member could advise, but not do the work. However, the team member was always in attendance throughout,toprovide skills transfer. The Critical Success Factors (CSFs) are not to be confused with the cascade of Mission Statements, which represented the key measures of the success for the ODP. There were 14 in total, out of these 5 were major (shaded), the full set is shown below in Figure 4:

\section{CRITICAL SUCCESS FACTORS for IT}

\begin{tabular}{|c|}
\hline LEADERSHIP \\
\hline SELF-MOTIVATION \\
COMMUNICATION \\
STAFF MANAGEMENT \\
\hline $\begin{array}{c}\text { DELIVERY of measurable } \\
\text { systems and service }\end{array}$ \\
IT CLARITY and MISSION \\
\hline PARTNERSHIP
\end{tabular}

\section{WORLDLY-WISE}

TRUST and LOYALTY

QUALITY

EMPOWERMENT

ATMOSPHERE teams, caring culture

Increased PRODUCTIVITY

Successful acquisition of SKILLS

Figure 4: Critical Success Factors.

Some of these factors derived from the high variance results of the Climate Survey:

- $\quad$ Leadership (1)

- $\quad$ IT Clarity and Mission (6)

- $\quad$ Partnership (7)

Other factors emanated from participant observation undertaken by the author:

- $\quad$ Leadership (1)

- $\quad$ Self-Motivation (2)

- $\quad$ Staff Management (4)

- $\quad$ Delivery (5)

- Worldly-wise (8)

- $\quad$ Trust and Loyalty (9)

- $\quad$ Empowerment (11)

Others linked with established company initiatives

- $\quad$ Quality (10)

- $\quad$ Empowerment (11)

Others came directly from the Needs \& Wants survey
- $\quad$ Communication (3)

- $\quad$ IT Clarity and Mission (6)

- $\quad$ Standards (14)

- $\quad$ Training (14)

- $\quad$ Teambuilding (2)

- $\quad$ Staff Management (4)

Factors 13 and 14 major Training Team technical challenges

(Factor 13-Increased Productivity was a corporate goal)

One factor was from the newly formed Top Team - Atmosphere (12).

The five Critical Success Factors were:

1. Leadership

2. Delivery

3. Partnership

4. Increased productivity

5. Skills acquisition

The ODP focused on six organisational dimensions, 


\section{Organisation}

2. Recruitment

3. Training

4. Human Resources

5. Communications

6. Skills Acquisition

Which were needed to restore organisational purpose, which is described in a $7^{\text {th }}$ dimension-the Deliverables, which included at the time the UK's largest migration programme.

\section{The ODP implementation}

The exploring phase of organisational change, which preceded the ODP, introduced the self-discovery teams, which set the scene for involvement of all levels within the IT Division. As well as activating the empowerment initiative which already existed in the rest of the organisation.

The ODP implementation started with four projects being chosen because of their importance to the CSF's:

1. Technical skills training

2. A revised Personal Appraisal process to ensure that 'Performance in Your Job' is the keystone of job appraisal, pay and career development.

3. How can we reduce the costs of IT whilst raising the quality of our performance?

4. Developing practical 2-way communication between IT and its external customers

5. Anextra project was added, due to a lack of office automation as follows:

6. Introducing the electronic office and the complimentary cultural change

Subsequently, two further projects 'PC Support' and the miniODP for the Datacentre were added.

Technical skills training constituted the following:

- Design

- Quality

- $\quad$ Requirements

- $\quad$ Teambuilding

- $\quad$ Financial control

- Technology intellect

Each reflected a particular skillset of individual Training Team members.

David Gilbert-Smith ${ }^{9}$ at The Leadership Trust originally devised the format of these project briefs, which were used in the so-called 'walk-away' method.
All the information a team needed to accomplish the task was $100 \%$ contained in the project brief. This enabled the Training Team member to focus on the group dynamics. The high reliability of this method having been used on at least 120 instances per year over a ten-year period.

The deployment of the Training Team mirrored the military modelin that they had an office instead of a house, they worked alongside their target departments and teams. At critical stages of the key deliverable-a large migration programme, they were always present. Similarly, when the staff undertook culture change initiatives e.g., team building, the Training Team acted as chaperones.

Due to time constraints, the Training Team members were trained in parallel for their own role. They received various briefings about Hearts \& Minds and used the research paper ${ }^{4}$ as a reference document. They also worked with intelligence and communications practitioners. This learning culminated in an 'Omani Evening', to which the architect of the civil reconstruction programme attended together with a former firqat member-then their Military Attaché in London.

\section{Results}

In this pilot, a Training Team was not used, but rather a small team of consultants to import much needed skills. Other omissions were the Climate Survey and a modified appraisal system to measure effectiveness.

The Top Team building was accomplished using the selfmotivation course devised for another organisation, which is summarised at the end of this section. This approach was used in its full form at the follow-on situation.

\section{Results of pilot}

Prior to restructuring, the organisation found to be fragmented; its management had become divisive; there was little leadership and equally there was little followership. A strong informal organisation operated which ran counter to the formal. This situation was further exaggerated by the lack of overall direction, due to the director position being vacant for some time. A number of people were found to be in need of counselling with their personal problems, which were affecting their work performance and their behaviour at work. Generally, there was a lack of dignity and self-esteem. In addition to the lack of leadership, there was also a strong lack of control in most aspects, such as budgetary control and staff management. In addition to the measures represented by the various sets of mission \& objectives, the author defined five critical success factors to measure the effects of the restructuring; the results are shown below:

\section{Staff turnover}

This was eliminated and indeed a few people who had left the organisation some time ago re-joined.

\section{Ability to recruit}

Confidence was rebuilt so that people were convinced that 
other people would want to join the organisation. Short lists were obtained and there was a good response for both management and staff needs. People of high calibre were also attracted.

\section{Ability to deliver}

A number of major projects were completed despite considerable problems caused by one of the project managers who were discovered to be seriously lacking in experience. This manager was successfully retained, counselled and embarked on a training programme to build experience for the long term, whilst at the same time not being labelled as a failure. The Top Team introduced proper controls themselves and deliverables took place in accordance with the new controls.

\section{Communication}

Monthly communication meetings were set up and attended by all members of the organisation, for which over time the staff themselves became responsible for organising and running. Two types of weekly progress meetings were also held for the Top Team, to reinforce their responsibilities, which focused on 1) Deliverables and 2) Staff issues. Furthermore, the performance of each Top Team member was reviewed each month using performance improvement plans, which were linked to the mission and objectives. Counselling was given to one member of the team, who was discovered to be immature for their years.

\section{Leadership}

All members of the Top Team underwent leadership training individually. These courses combined working as a team, leading that team in a variety of circumstances, all of which were analogous to the workplace as well as involving practical work. They were subsequently encouraged to transpose these newfound techniques, particularly team review and planning in their own teams. They also replicated the weekly staff review meetings in their own teams and planned their own team building exercises. Two members of the Top Team, who lacked staff management experience, received fortnightly coaching sessions to further assist in the team leadership acquisition process.

\section{Results of the large implementation}

The results of the five main CSFs are described as follows:

\section{Leadership}

Leadership training starting with the Top Team successfully dismantled the previous' committee culture', managers took responsibility and staff management was also introduced.

\section{Delivery}

Delivery was remarkable, having experienced two previous failures.

The IT Division deliveredat the time the largest computer migration programme ever undertaken in the UK.
The programme covered a series of line-by-line conversions of 7 majorprojects and a raft of 5 major and 9 minor redevelopment projects-21 projects overa 3-year period, involving 800 man-years of effort and migration of approximately ${ }^{9}$ million lines of code. The programme also included the largest $\mathrm{DB} / 2$ database conversion in the world.

The programme was completed a few days early and was even $4 \%$ under budget. It allowed the entire Group to provide continuous production services without any significant degradation of service levels.

\section{Partnership with customers}

The restructuring of the Division and importing of Business Systems Centres andpartnering behaviours from British Airways was key to repairing the relationship betweenthe IT Division and the rest of the Group. Best practice governance for project delivery was also introduced.

\section{Increased productivity ${ }^{10}$}

- $\quad$ Development productivity was improved by $9.3 \%$

- Datacentre unit costs reduced by $2.5 \%$

- $\quad$ All Datacentre service levels achieved

\section{Successful acquisition of skills}

All the ODP skills projects were completed and absorbed in a Hearts \& Minds way; in particulara formal Design Authority was established together with competent estimating and planning

These results weresignificant that the staff produced a video ${ }^{11}$ themselves to celebrate their success including a review of the five major CSF's.

\section{other achievements:}

- $\quad$ BCS Award for the Migration Programme (1994)

- $\quad$ ISO 9001 certification-the successor to BS5750

- 1995 Winners of the Challengers Trophy

\section{Discussion}

During the original research, when the attributes of Hearts \& Minds began to emerge such as persuasion and incremental beliefs, the significance of Needs \& Wants ${ }^{v}$ became clear as did the requirement to work within the target culture in order to change from within.

The impact of Needs \& Wants was pilot tested, ${ }^{12}$ the effects of which are discussed at the end of this section. An example 'want' was fixing the squeak in the air-conditioning unit and examples of a 'need' were as follows:

- More technical knowledge of communications networks

- $\quad$ A COMPAQ portable PC with a printer

${ }^{\mathrm{V} E q u i v a l e n t}$ to Deprivations \& Luxuries respectively 
Unqualified delivery of these Needs \& Wants was also noted as a necessity.

In the pilot, a Training Team was not used, but rather a small team of consultants to import much needed skills. Other omissions were the Climate Survey and a modified appraisal system to measure effectiveness.

The Top Team building was accomplished using a selfmotivation course ${ }^{13}$ devised for another organisation, which is summarised at the end of this section and also used in its full form at Sun Life.

\section{Final version ${ }^{8}$}

\section{The Vision}

The IT Division formulated its own vision (equiv. Mission Statement), which was a subset of the corporate Vision. The IT Division Mission Statement was cascaded down into each Department, who identified their own contribution and then ultimately down to a personal level, in the form of appraisal objectives, where the values were given a $50 \%$ weighting.

\section{Needs \& Wants}

Openness was the order of the day. This was published and the Top Team tasked in an inverted hierarchical way to deliver at all costs to their staff. Staffs were frequently given opportunity to give feedback on the performance of their management regards the delivery. At first management found this uncomfortable, but power was used wisely by all and delivery was achieved and gratefully received.

\section{Awareness and communication}

Refuge was taken in kaizen, i.e. staff own their processes. In other words, these functions were self-administrated by the target audience under review. This dispelled any fears that they were being spied on, because they were observing themselves; they learnt a reoccurring theme-'use power wisely', because the Awareness Team had direct access to the author when a key problem arose. Equally, the Communications Team was given privileged access to Top Management reports and again quickly learnt to use power wisely. None of these teams ever compromised the Top Team.

One of the projects was to devise a monthly communications meeting, which was first was facilitated by the Top team, but then handed over to the Communications Team. Diagonal Cross-sectional teams were used throughout with single status. The Training Team were deployed to coach these two teams with very good results. The 'Exploring Phase' introduced the self-discovery teams, which dismantled the hierarchical behaviours by involvement irrespective of level within the IT Division as well as activating the empowerment initiative, which already existed in the rest of SunLife. In parallel the Climate Survey was conducted and the Training Team were introduced. To aid the exploring, small projects were undertaken by diagonal-cross section teams, which focused either on urgent improvement (e.g. DB/2 education; Capacity analysis; PC Support; Communications; Customer Service), or discovery learning primarily to address low awareness.

After the diagnosis phase when the following were identified:

- $\quad$ Climate Survey Results

- $\quad$ Needs \& Wants

- Participant observation

- $\quad$ Critical Success Factors

Participant observation determined the implementation style and yielded the following:

- Very old hierarchical organisational structure

- $\quad$ Two previous programme failures

- $\quad$ Loss of dignity

- $\quad$ Captive audience with 5 million lines of undocumented code

- $\quad$ 10-year track record of non-delivery

- 'The South-West windsock' inhibits awareness

- $\quad$ The 'Untouchables'

- $\quad$ Lack of Communication between staff and management

- $\quad$ Over-use of external Consultants

It was recognised that despite the poor track record of the target audience that they were the only population that could accomplish the task, because they had committed to memory the key aspects in the absence of any documentation.

It was also clear that their work setting was key in terms of the following:

- Removal of distractions

- The right type of help and support

- Unqualified delivery of their 'Needs'

- Reward of good performance with their 'Wants'

- $\quad$ Clarity of purpose

- $\quad$ Realisation of the real world

- Divisive communication

- Normal behaviour

It became clear that a persuasive method would need to be chosen and that a pro-active style of Change Agents would be needed to support the changes. With a population of some 550, a team would be needed. Reflection against the research already performed made this a suitable set of circumstances for the use of Hearts \& Minds.

\section{Needs \&wants}

These are shown in the two tables in Figure 5: 


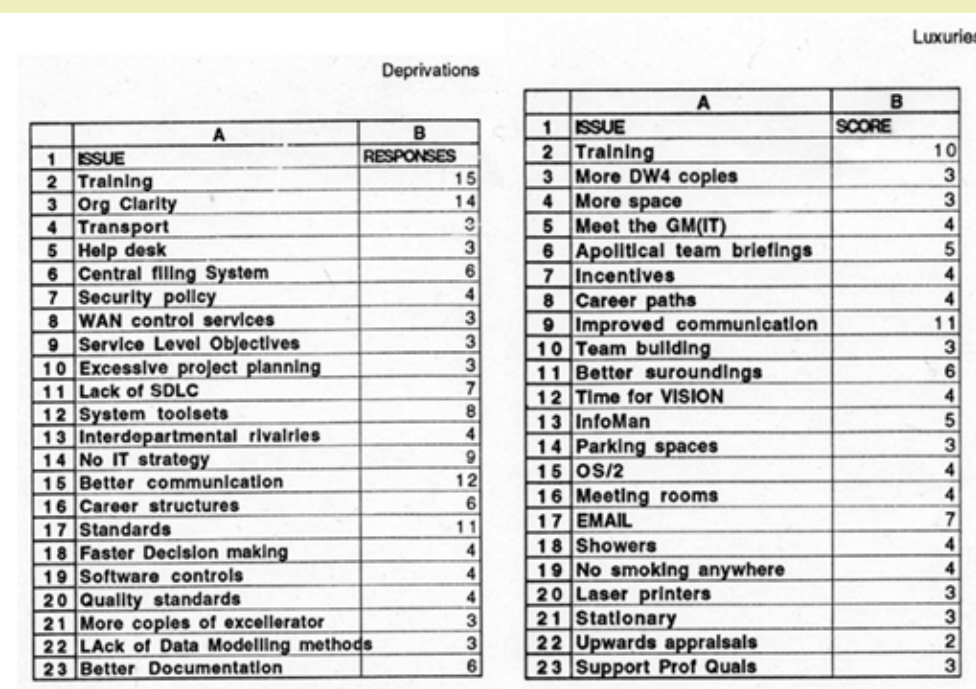

Figure 5: Needs and Wants.

The most interesting aspect is that Communication appears in both, being ranked third as a Need (=Deprivation) and ranked top as a Want (=Luxury).

\section{Lack of permanence}

Conventional methods often use rote learning and avoid addressing belief. These methods offer no link between the situation of the target audience and resolving their problems. Further, in commercial terms there is no focus on achieving the mission. Under these circumstances, people often participate to achieve ' $a$ tick in the box', but little else. Often people quickly return to type. To participate, staff often learns by rote and as such their understanding is minimal. In order to achieve permanence, a number of techniques were deployed, using hearts \& minds as the foundation.

In the original research ${ }^{4}$ provided a succinct description of what Hearts \& Minds is not:

"Hearts \& Minds is not coercion, it is founded on persuasion. In other words, it is not dictatorship; it is not ordering, it is the changing of attitudes, it is appealing to people, it is motivating people to do things differently, it is opening their minds. Above all, it is getting people to do things differently, because they are convinced and because they want to do it. A successful conclusion occurs when the people have identified with the new ideas, they have assimilated them and they have internalised the ideas to become additional to their own set of beliefs."

One of the most important aspects is to avoid intrusion into core beliefs, with obvious examples being religion and football. In a similar way to kaizen, people can quickly be persuaded if their lot can be improved.

"Kaizen offers doing the same amount of work with less effort"14

In a similar way, all the results of the Needs \& Wants survey must be delivered $100 \%$ without fail. Unless this is done, change will not occur; permanence will develop if these changes are maintained. Hearts \& Minds features high reliability because it operates within the value system of the target audience. Further, it focuses on the Needs \& Wants of the audience. No successful change is ever made by relying upon the target audience to self-administrate the change nor can it be made successful by strong-armed methods. The Training Team is a unique phenomenon, it supports the front-line, it does not do things for people, but concentrates on training and equipping people to help themselves. It is very powerful.

Sun Life was the very first realisation that Hearts \& Minds previously employed for changing whole countries could be used to change commercial organisations. It is also a testament to sustained change and without further intervention, the change lasted 10 years before the organisation was outsourced.

Common perceptions of Hearts \& Minds appear in the following contexts:

- The Malayan Campaign itself

- $\quad$ Other theatres of war-Borneo

- $\quad$ Marketing

- It's use as a slogan

Hearts \& Minds is a consistent and reliable methodology, the key features being:

- $\quad$ Careful diagnosis

- $\quad$ Restores loyalty

- Operates in the value system of the target audience

- $\quad$ Focuses on needs and wants of the target audience

- Provides support to the target culture, which works alongside

- Rejuvenates the target culture 
There are three key characteristics namely:

1. Persuasion

2. Training Teams

3. Permanence

"Hearts \& Minds is not coercion, it is founded on persuasion. In other words, it is not dictatorship; it is not ordering, it is the changing of attitudes, it is appealing to people, it is motivating people to do things differently, it is opening their minds."

In Case Study $1^{8}$-the Training Team mimicked the military experience of the BATT (British Army Training Team) in the Dhofar, who lived and worked alongside the tribal groups [the Firqats ${ }^{\mathrm{VI}}$ ]. This role was unique-it was neither a consulting role nor involved membership of the Firqats. The Training Team learnt the context of the overall mission - i.e. Hearts \& Minds must have an objective. Yes, the war in the Dhofar had to be won, but why? The prevailing risk was of wider conflict resulting in the closure of the Straits of Homuz and control there after by PDRY/USSR strangling oil supplies to the US and Europe. However, for the Dhofar the ultimate reason was to bring about a civil modernisation and the building of a proper infrastructure.

A change guru described Sun Life ${ }^{15}$ as, "An interesting story of rampant chaos, which was resolved by applying converging 1) Programme Management and 2) Actual learning." Infact, very little learning had taken place for some years and it was breathtaking that the cloned implementation of Operation Storm experience worked in the same way. The target audience was not tribal, but there were similarities. They were proud and had been revered technicians; they had been taken over not by the enemy, but by hordes of consultants, who had suffocated their skills and way of life. They did not seal the water wells, but the consultants embarked on tangents to suit their own revenue needs. In short, it was the consultants who did the work and who owned the change with the Client spectating the work.

Another key similarity was the SEPs. After ten years, members of the IT Division became converts, recovered their dignity and once again became successful. One member even realised their true potential and emigrated to the United States, becoming a Vice President of Business Operations for Oracle. Eventually, the Training Team completed their task and trained the Middle Management to take-on their roles, who were also repatriated with their rightful position in the organisation.

\section{The value of permanence}

The real value of permanence is obviously economic, since it avoids recursive 'refresher change initiatives' and the attendant costs. However, the underlying significance lies in its sincerity to the people involved, because it will change their lives.

Case Study $3^{16}$ - Energis shows what can happen, when the correct diagnosis has been performed, staff convinced, mobilised and then terminated due to lack of management commitment. There is never a second chance. People had dropped their defences, they had seen the light and some had even seen a chance at that early stage of bettering their careers. Reversal of those opportunities can never be recovered, but change is a perishable commodity.

In the converse, many years later, the target audience of Operation Storm and SunLife are still in touch with their Training Team(s) and still proud of their new lot and realised benefits.

The original change has been sustained, because it took place within their value system, supported by a Training Team, who over time made the audience the owners and ensured that support was in place to sustain the change.

The same level of sustained change has also been observed with various NHS organisations.

The real focus of Hearts \& Minds lies in improving the lot of the target audience in a permanent way and ensuring that they are equipped to maintain that change by not only possessing new skills, but more importantly from within their own set of beliefs.

\section{The way forward and applications}

Case Study $2^{17}$-Wesleyan Assurance underwent radical change themselves, but the case study is about how Hearts \& Minds was applied to their major supplier.

Again, there were parallels with Dhofar, because the problems were centred on:

- $\quad$ Previous failures of management

- Multiple tribal enclaves

- $\quad$ Single focus to make a profit

The biggest challenge was to address the tribal factions or as the Wesleyan described it, "We bought a programme team from you [the Service Provider] to deliver the programme, not a set of different groups, who work separately."

To do this the following actions were addressed:

- To integrate all staff in the programme irrespective of their owning unit

- For everyone to become members of a programme team

- To behave that way and relate to the Client in that manner

- $\quad$ Establish a programme culture and break down barriers

As in SunLife, the need for better communication triggered the deployment of Hearts \& Minds, starting with Needs \& Wants. This was followed by the formulation of a mission statement, (this time suggested by the staff themselves), which was reinforced with a modified appraisal system to measure the values.

Returning to the challenge of building single programme culture. To do this the self-motivation course designed for Sun Life was modified to build 'performing teams' implemented, which embraced Hearts \& Minds in every aspect. This gave confidence and 
the technical problems, most which crossed team boundaries were quickly solved with the help of the Training Team. Again, following Sun Life experience the relationship with the Client was rebuilt using partnering, which had the effect of gaining trust of the Client and for their part reciprocated by showing respect-both of which had been previously lacking.

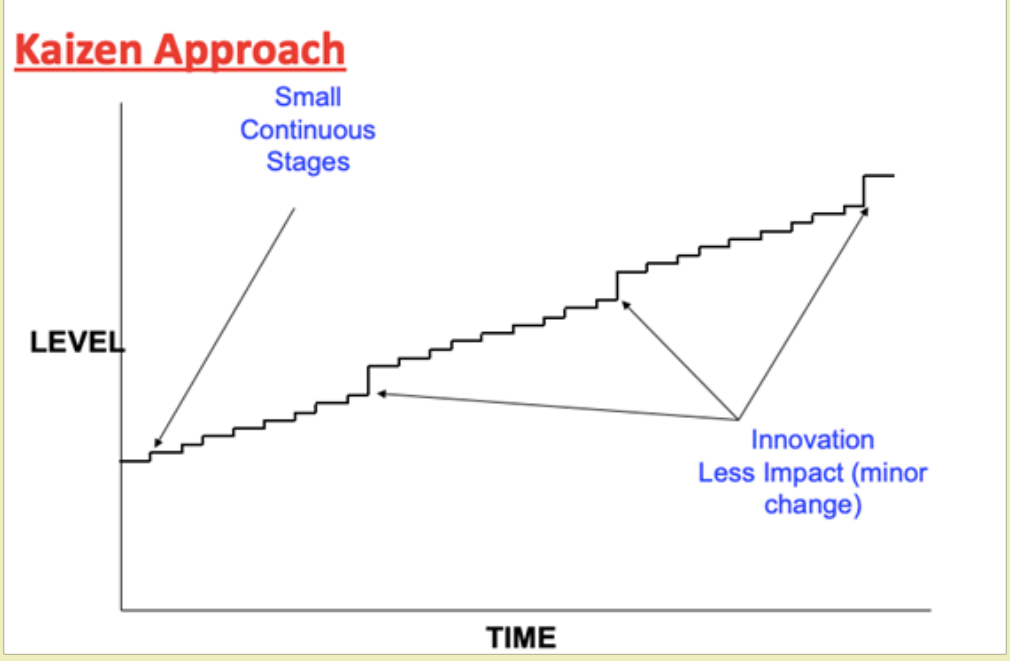

Figure 6: The Inverted Triangle.

\section{Conclusion}

Hearts \& Minds focuses on the needs of the target audience and works within their values.Considering kaizen as a comparison; the 'Inverted Triangle' ${ }^{18}$ involves front-line staff to innovate with small ideas on a continuous basis (Figure 6). Because the changes are small, there is less impact compared with large step changes and of course as already discussed enables staff to do 'the same amount of work with less effort'. Here are some examples: ${ }^{\mathrm{VII}}$
- $\quad$ Fixing torches to power tools, so operatives can see where they are working.

- A seat mounted on a skateboard attached to the assembly line for a short distance that swings inside the car body to avoid sitting on sharp edges and protruding bolts (Figure 7).

Of course, these changes are sustained since the staff invented the changes as well as making their jobs easier.

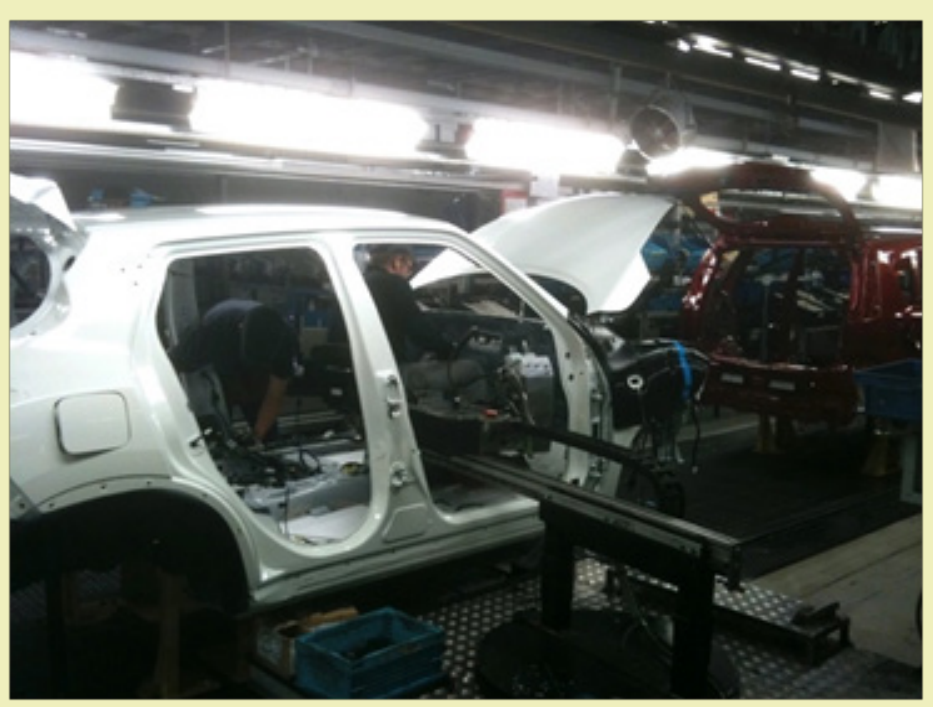

Figure 7: Example of Kaizen - skateboard mounted seat.

Operation Storm also offers some further examples.

Communism does not go hand-in-hand with Islam. ${ }^{19}$
The communist representation in PDRY was multifactional and included not only Russians, but also the Chinese and the Cubans, each of whom had separate roles. Their approach of 're-education' 
was to close the mosques, eradicate religion and send some of the tribal leaders away to Moscow for training. The approach taken by the Training Team was the opposite and one of using their religion [the Dhofaris], to 'square them away', as had been the case in Malaya.This was a fundamental technique to re-annexing the Dhofar from PDRY. ${ }^{\mathrm{VIII}}$ The military established physical lines progressively moving East to West until all Dhofar territory was reclaimed. The military would establish a fortified line and clear the ground behind it. Civil Aid would then move in to affect a handover from the military. They would then pacify the area and give locals some reason to be on the Government side. Example lines below are shown on the map which follows (Figure 8). ${ }^{20}$

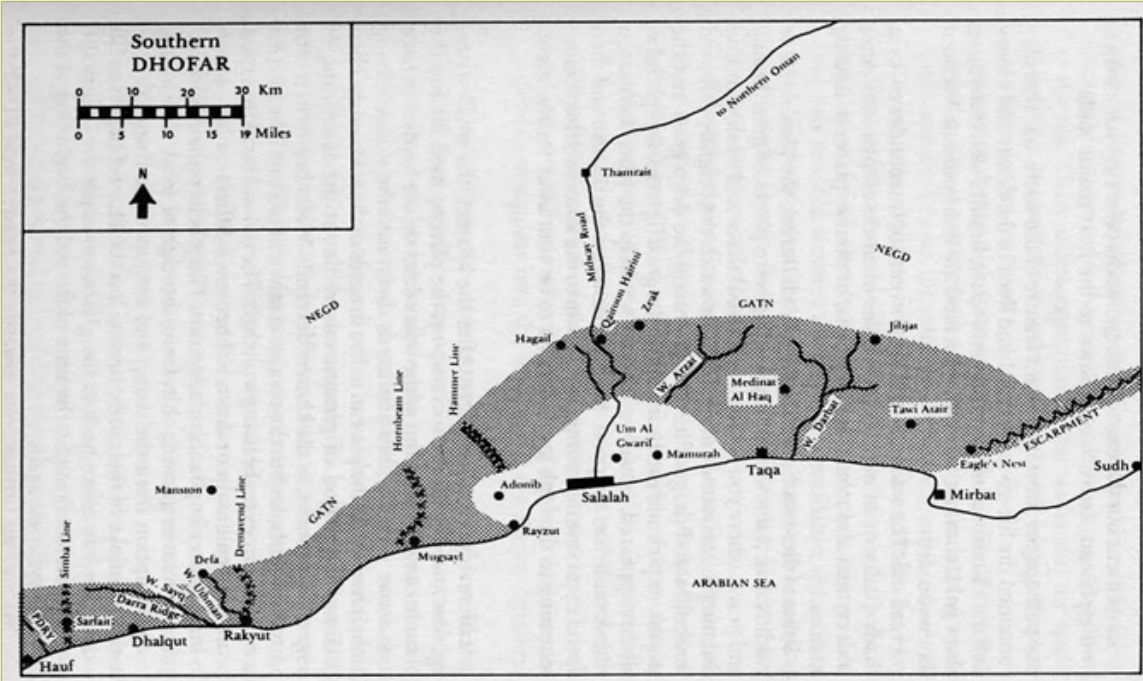

Figure 8: Map of Southern Dhofar.

- Hammer

- Hornbeam

- $\quad$ Demavend

- $\quad$ Simba

They used Taylor Woodrow wooden prefabricated buildings to establish civil centres behind these lines and typically they would consist of:

- A Mosque

- Schools

- $\quad$ Medical Centre

- $\quad$ Stores [shops]

- $\quad$ Radio Room

Civil Aid would 'bring them back to Islam', because they were ashamed of being 'Godless'. As reinforcement, they provided rations [food] at low prices and tentage. The population were typically local tribesmen who were 'religiously bent'. Schools were very often staffed by Egyptian school teachers and the medics were also often Egyptian and sometimes Sudanese. The focus was very much on reverting back to local values and culture.

"We gave, they lost something" in other words, "they had to be given something to lose". They were party to this. Nothing was ever done for them entirely $100 \%$, there was always a contribution from them. Civil Aid would provide the materials, but they would build it and therefore acquire ownership and were party to it. An example was water wells, they would build them with Civil Aid providing the expertise.

Both of these examples demonstrate the effectiveness of the Hearts \& Minds mechanisms, which in turn achieve high levels of permanence, so to summarise:

- Like the 'Inverted Triangle', fixes problems that are important to the target audience, not the Administrators or C-suite

- $\quad$ Addresses Needs \& Wants of the target audience

- $\quad$ Allows the target audience to participate

- The target audience are given the skills by a Training Team, who chaperone throughout the task

- The Training Team always work within the values of the target audience

- $\quad$ Dignity is maintained at all times

Like kaizen, Hearts \& Minds puts the target audience in control of their own destiny and whilst the comparison of transforming a country with transforming an organisation at first seems odd. However, it is not the size of the population that is being changed that matters, but rather the effectiveness of the underlying mechanisms, which work equally well for both extremes. Finally, Britain was a 
colonial power, which well positioned it to understand many other cultures. Perhaps this is the reason for its unbroken track record of success with Hearts \& Minds both in the military and in business?

\section{Acknowledgments}

Professor Jonathan Blackledge, Stokes Professor, Science Foundation Ireland, Honorary Professor, School of Electrical and Electronic Engineering, Technological University Dublin, Ireland.

Hughie Vernon, ex-BATT, Operation Storm

Trevor Henry, Civil Liaison Officer Dhofar, Operation Storm

Keith Farnes, ex-BATT, Operation Storm

Oman Military Attaché, London

Charles Linford, ex-BATT, Operation Storm

Alf Bell, Training Department, Nissan Manufacturing UK (NMUK).

\section{Funding}

Chris Davies \& Associates Limited.

\section{Conflicts of Interest}

Author declares that there is no conflict of interest.

\section{References}

1. Cloake J. Templar Tiger of Malaya. London: Harrap; 1985.

2. Dickens P. The Jungle Frontier. Fontana; 1984

3. Niven BM. Special Men, Special War. Imago Productions, 1992.

4. Davies C. Hearts and Minds: the role in commercial organisational restructuring. British Psychological Society submission, Chris Davies \& Associates Ltd.; 1991.
5. Davies C. Sustained Organisational Change: A Hearts and Minds Approach. Loughborough University; 2008. p. 40-46.

6. Litwin GH, Stringer RA. Motivation and Organizational Climate. Boston: Harvard Business School Press; 1968.

7. Davies C. Sustained Organisational Change: A Hearts and Minds Approach, Loughborough University; 2008. 52 p.

8. Davies C. Sustained Organisational Change: A Hearts and Minds Approach, Case Study 1. Loughborough University; 2008. p. 8-81.

9. Gilbert Smith D. Founder of The Leadership Trust. 1975.

10. Dryland K. QDC, Benchmarking and Productivity. 1994.

11. Mott P, Mays C. The Spirit of IT. Sun Life Corporation; 1993.

12. Private discussion with Ian Gilbertson. Bermuda; 1990

13. Vernon H. Teambuilding Course Notes. Hugh Vernon Training; 1996

14. Handyside E. Genba Kanri: the disciplines of real leadership and continuous improvement in the workplace. Productivity and Physical Effort, Gower; 1997. 32 p.

15. Private discussion with Bob Garratt, author of The Learning Organization. Harper Collins: 2001.

16. Davies C. Sustained Organisational Change: A Hearts and Minds Approach. Case Study 3, Loughborough University; 2008. p. 118-138.

17. Davies C. Sustained Organisational Change: A Hearts and Minds Approach. Case Study 2, Loughborough University; 2008. p. 97-117.

18. Nissan Manufacturing UK. Continuous Improvement Approach. 2013.

19. Meeting Note with Trevor Henry. Benitachell: Spain; 2004.

20. Jeapes T. Operation Oman. [map of] Southern Dhofar, William Kimber; 1980. 